\title{
How I Treat Adult Acute Lymphoblastic Leukemia in India
}

\author{
Prasanth Ganesan ${ }^{1}$ Smita Kayal ${ }^{1}$ \\ ${ }^{1}$ Department of Medical Oncology, Regional Cancer Center, \\ Jawaharlal Institute of Postgraduate Medical Education \& Research \\ (JIPMER), Puducherry, India
}

Ind J Med Paediatr Oncol 2021;42:584-594.
Address for correspondence Prasanth Ganesan, MD, DM, Medical Oncology, 3rd Floor,Superspecialty Block (SSB), Jawaharlal Institute of Postgraduate Medical Education \& Research (JIPMER), Dhanvantari Nagar, Puducherry 605006, India (e-mail: p.ganesan@jipmer.edu.in).

\section{Introduction}

Survival in pediatric acute lymphoblastic leukemia (ALL) has improved from less than $10 \%$ (in the 1960s) to over $90 \%$ in developed countries. ${ }^{1}$ These improvements were driven by optimized, risk-stratified chemotherapy and enhanced supportive care. The incorporation of tyrosine kinase inhibitors (TKIs) in Philadelphia chromosome-positive ( $\mathrm{Ph}+\mathrm{ve})$ ALL has improved survival in this subset. ${ }^{2}$ However, older age makes significant impacts on survival in ALL. Though the survival among adolescents and younger adults (AYA, 19-40 years) has improved (5-year survival: 50-70\%), gains in older adults (41-60 years) with ALL have been more modest (5-year survival: $30-40 \%)^{3,4}$ Even in the best centers in the world, till recently, survival among "elderly" ALL ( $>60-65$ years) was poor, and only 10 to $15 \%$ were being "cured" with conventional chemotherapy. ${ }^{3,5}$

Adverse disease biology partly explains the drop in survival with age. ${ }^{6}$ Older patients have higher proportions of Ph-positivity, and "Ph-like" changes, with a lesser proportion with "good risk" cytogenetics like the $t(12 ; 21)$ translocation. Better outcomes are demonstrated in AYA ALL with intensive ("pediatric-type") chemotherapy protocols. ${ }^{7,8}$ However, these regimens have increased toxicity and treatment-related mortality (TRM), especially in older individuals and "real-world" patients. ${ }^{9-12}$ India has the highest population of adolescent and young adults globally, and most centers see a significant proportion of patients in this age group. ${ }^{13,14}$ Indian centers report a high incidence of infectious complications (including multidrug resistant bacterial infections) during delivery of intense therapies for acute leukemias. ${ }^{15,16}$ Even if minimal residual disease (MRD) assessment is done, there is limited access to stem cell transplantation. ${ }^{14}$ Thus, multiple factors contribute to poorer outcomes in adult ALL, and the challenges are country and center specific.

In this review, we use a series of representative case scenarios to discuss the management process in adult ALL. The discussions focus on presenting the standard of care while simultaneously highlighting issues specific to India. The broad principles of the decision-making process are outlined without too much detailing of the features of individual protocols.

\section{Case 1: Young Adult with Standard-Risk Acute Lymphoblastic Leukemia}

A 32-year-old female, housewife, mother of two children from a poor socioeconomic background presented with weakness and recurrent fever for 2 months. Her presentation blood counts were: hemoglobin $50 \mathrm{~g} / \mathrm{L}(5 \mathrm{~g} / \mathrm{dL})$, white blood cells (WBCs): $23.4 \times 10^{9} / \mathrm{L}\left(23,400 / \mathrm{mm}^{3}\right)$, and platelets: $34 \times 10^{9} / \mathrm{L}\left(34,000 / \mathrm{mm}^{3}\right)$. Peripheral smear showed $65 \%$ blasts. Bone marrow was completely replaced by blasts confirmed as precursor B-cell (pre-B) lymphoblastic leukemia by flow cytometry. Conventional cytogenetics showed normal karyotype, and reverse transcription polymerize chain reaction (RT-PCR) for
DOI https://doi.org/ 10.1055/s-0041-1731979. ISSN 0971-5851.
(C) 2021. Indian Society of Medical and Paediatric Oncology. All rights reserved.

This is an open access article published by Thieme under the terms of the Creative Commons Attribution-NonDerivative-NonCommercial-License, permitting copying and reproduction so long as the original work is given appropriate credit. Contents may not be used for commercial purposes, or adapted, remixed, transformed or built upon. (https://creativecommons.org/ licenses/by-nc-nd/4.0/)

Thieme Medical and Scientific Publishers Pvt. Ltd., A-12, 2nd Floor, Sector 2, Noida-201301 UP, India 
BCR-ABL was negative. She started induction therapy with modified BFM-95 protocol.

\section{Adult versus Pediatric protocols}

Multiple trials have shown superior results using "pediatric" type protocols in AYA patients with ALL (-Table 1). ${ }^{17-19}$ Patients up to the age of 50 years have been included in these studies, and the current consensus is to use pediatric protocols whenever feasible for treating young adults. At our center, we use BFM-95, a standard and frequently-used "pediatric" regimen. Inadequate prednisolone response and adverse biology (BCR/ABL or MLL rearrangements) are considered high-risk, while, T-cell ALL (T-ALL), older ages ( $>6$ years), and initial $\mathrm{WBC}>10 \times 10 / \mathrm{L}$ constitute medium risk. We used a modified version of this protocol where most patients received the standard risk treatment with modifications done only for those who are MRD+ve. ${ }^{20}$ Previous studies from India (-Table 2) have reported 40 to $60 \%$ survival among AYA ALL treated with this protocol. ${ }^{12,14}$ Though higher TRM was noted in older Indian studies, a large multicenter study from India has shown that pediatric protocols can safely be delivered in AYA patients without excess mortality. ${ }^{11,14}$ Concerns about toxicities remain and, even in developed countries, a quarter of AYA patients are treated with "adult" protocols. ${ }^{21}$

\section{Case-1 Continued}

At the end of induction, the bone marrow (day 35) was in remission, and MRD was negative $(<0.01 \%)$. She continued standard therapy (phase Ib followed by high-dose methotrexate, reintensification [IIa and IIb], prophylactic cranial radiation [dose: $12 \mathrm{~Gy}$ ], and maintenance). During maintenance, she frequently delayed her follow-up visits leading to treatment interruptions. She and her husband were counseled multiple times by a social worker to maintain adherence. Ultimately, she completed 2 years of maintenance therapy and remained in CR 6 months after completing treatment.

\section{Role of Cranial Radiation}

Prophylactic cranial radiation is usually used in adult ALL, while newer pediatric protocols omit this in low-risk disease. Concerns about long-term radiation effects (neurological and neuroendocrine) may be lower in an older individual compared with a very young child. ${ }^{22}$ At our center, we choose to continue to offer cranial RT for adult ALL to reduce the risk of CNS relapses.

\section{Role of Rituximab}

Conventional chemotherapy based on "pediatric" protocols yields survival of 50 to $60 \%$ in AYA ALL. ${ }^{4}$ Addition of rituximab has improved event-free survival (EFS) by $10-15 \%$ without a statistically significant improvement in overall survival [OS] in CD20+ adult ALL treated in the GRAALL2005/R study (which used the GRAALL 2003/2005 backbone of chemotherapy, an intense "pediatric-type" regimen). ${ }^{23}$
This is another consideration in CD20+ve patients (about one-third of pre-B ALL), reducing relapse by 10 to $15 \%$. At our center, we usually do not add rituximab for all patients due to cost considerations.

\section{Role of Counseling and Maintaining Treatment Adherence}

Nonadherence and abandonment occur in 11 to $15 \%$ of Indian ALL patients. ${ }^{11,14,24,25}$ Young adults have to tackle multiple social and economic issues. These patients have a high risk of demotivation and nonadherence which may manifest during the long treatment course. Treatment delays reduce the relapse-free survival from $69 \%$ to $43 \%{ }^{12}$ The benefits of an "intensive" regimen will not be realized unless the patients strictly adhere to the treatment timelines. It is vital to have a team of supportive personnel (social workers, psychooncologists, etc.) who can work closely with these patients and proactively identify nonadherent behavior and intervene appropriately to realize maximum benefit. Oncologists/hematologists involved in the care of leukemias should make attempts to get adequate support (social workers/psychooncologists/support from nongovernment organizations [NGOs]) to prevent treatment nonadherence and abandonment. Experience from pediatric ALL shows that it is possible to achieve this, even in a governmental setup. ${ }^{26-28}$

\section{Case 2: Adult Acute Lymphoblastic Leukemia with High-Risk Disease}

A 49-year-old male presented with a 1-week history of breathing difficulty and facial puffiness. He had neck nodes, mediastinal widening, and superior vena cava (SVC) syndrome. Hemogram showed hemoglobin: $100 \times 10^{9} / \mathrm{L}(10$ $\mathrm{g} / \mathrm{dL})$, WBC count: $112 \times 10^{9} / \mathrm{L}\left(112,000 / \mathrm{mm}^{3}\right)$, and platelet counts: $98 \times 10^{9} / \mathrm{L}\left(98,000 / \mathrm{mm}^{3}\right)$. Peripheral smear showed $90 \%$ blasts, and bone marrow with phenotyping confirmed a diagnosis of T-cell lymphoblastic leukemia (positive: CD3, CD7, CD5, terminal deoxynucleotide transferase (TdT); negative: CD19, CD10). There were no neurological symptoms, hypoxia, and cerebrospinal fluid was negative for malignant cells. After establishing hydration and measures to control tumor lysis, he started BFM-95 induction.

\section{T-Cell versus B-Cell Acute Lymphoblastic Leukemia}

T-ALL comprises approximately 15 to $25 \%$ of total cases of adult ALL. ${ }^{29,30}$ T-ALL is more likely to have higher white cell count, mediastinal enlargement, and CNS involvement. ${ }^{31-33}$ Historically, outcomes in T-ALL outcomes were inferior, but with contemporary risk-adapted protocols, survival has improved to $85 \%-90 \%$ in pediatric T-ALL. Adult trials of German multicenter study group for adult ALL (GMALL), group for research on adult ALL (GRAALL), UKALL, and hyper-CVAD have shown CR rates of 75 to $90 \%$ and 5-year OS of 35 to $50 \%$ for T-ALL. ${ }^{34,35}$ However, in AYA patients, intense protocols with dexamethasone, higher intensity of L-asparaginase and high-dose methotrexate $(5 \mathrm{~g} / \mathrm{m})$ yields survival of 60 to 
Table 1 Comparison of adult and pediatric protocols

\begin{tabular}{|c|c|c|c|c|}
\hline $\begin{array}{l}\text { Component of } \\
\text { therapy }\end{array}$ & Pediatric & Adult & $\begin{array}{l}\text { Our preference in } \\
\text { adult ALL therapy }\end{array}$ & Remarks \\
\hline Steroids & $\begin{array}{l}\text { Higher cumulative } \\
\text { doses } \\
\text { Dexamethasone }> \\
\text { prednisolone }\end{array}$ & Lesser doses overall & $\begin{array}{l}\text { Prednisolone } \\
\text { Though dexamethasone may } \\
\text { reduce relapses, there is a } \\
\text { higher risk of infectious } \\
\text { complications }\end{array}$ & $\begin{array}{l}\text { High risk of hyperglyce- } \\
\text { mia and infections in } \\
\text { adults }\end{array}$ \\
\hline L-asparaginase & $\begin{array}{l}\text { Higher cumulative } \\
\text { doses }\end{array}$ & Lesser doses & $\begin{array}{l}\text { We usually cap the dose of L- } \\
\text { asparaginase at } 10,000 \text { when } \\
\text { using the BFM protocol. For } \\
\text { older individuals above } 50-60 \\
\text { we minimize the use of L- } \\
\text { asparaginase or omit this dur- } \\
\text { ing induction }\end{array}$ & $\begin{array}{l}\text { Risk of complications is } \\
\text { very high in individuals } \\
\text { over } 50\end{array}$ \\
\hline Peg-asparaginase & $\begin{array}{l}\text { Most modern protocols } \\
\text { have switched to peg }\end{array}$ & $\begin{array}{l}\text { Most modern protocols } \\
\text { have switched to peg }\end{array}$ & $\begin{array}{l}\text { With peg-asparaginase avail- } \\
\text { ability from Indian companies, } \\
\text { the cost has reduced; but it is } \\
\text { still higher than conventional L- } \\
\text { asparaginase. We do not use it } \\
\text { regularly because of the cost } \\
\text { issues }\end{array}$ & $\begin{array}{l}\text { Though the efficacy is } \\
\text { similar to conventional } \\
\text { asparaginase, the com- } \\
\text { pliance may be im- } \\
\text { proved with the peg } \\
\text { preparation }\end{array}$ \\
\hline Vincristine & $\begin{array}{l}\text { Higher doses } \\
\text { Some pediatric proto- } \\
\text { cols do not cap at } 2 \mathrm{mg}\end{array}$ & $\begin{array}{l}\text { Capped at } 2 \mathrm{mg} \text { per } \\
\text { dose } \\
\text { Lower cumulative doses }\end{array}$ & $\begin{array}{l}\text { Capped at } 2 \mathrm{mg} \text {. When used as } \\
\text { prophylaxis drugs like vorico- } \\
\text { nazole can worsen toxicity; } \\
\text { hence withhold } 24 \text { hours be- } \\
\text { fore vincristine }\end{array}$ & $\begin{array}{l}\text { High risk of neuropathy } \\
\text { in adults }\end{array}$ \\
\hline Methotrexate & $\begin{array}{l}\text { Higher doses like } 5 \mathrm{~g} / \mathrm{m}^{2} \\
\text { easily delivered } \\
\text { Recent data with Capiz- } \\
\text { zi's type regimens }\end{array}$ & $\begin{array}{l}\text { Creatinine clearance } \\
\text { issues in individuals }>50 \\
\text { years; hence } \geq 5 \mathrm{~g} \text { is } \\
\text { difficult to administer. } \\
\text { No data with Capizzi's } \\
\text { type methotrexate }\end{array}$ & $\begin{array}{l}\text { We use a } 3 \mathrm{~g} / \mathrm{m}^{2} \text { dose for pre-B } \\
\text { ALL and } 5 \mathrm{~g} / \mathrm{m}^{2} \text { for T-ALL when } \\
\text { using BFM protocol }\end{array}$ & $\begin{array}{l}\text { Risk of nephrotoxicity, } \\
\text { especially in older indi- } \\
\text { viduals. Need for drug- } \\
\text { level monitoring }\end{array}$ \\
\hline $\begin{array}{l}\text { AlloSCT in first } \\
\text { remission }\end{array}$ & $\begin{array}{l}\text { Usually not considered } \\
\text { except for persistent } \\
\text { MRD+ or MLL rear- } \\
\text { rangements } \\
\text { Many protocols prefer } \\
\text { intensification }\end{array}$ & $\begin{array}{l}\text { Usually considered for } \\
\text { MRD positive, Ph+ve, } \\
\text { MLL rearrangements, } \\
\text { and other protocol de- } \\
\text { fined high-risk features }\end{array}$ & $\begin{array}{l}\text { CR1 alloSCT is offered for high- } \\
\text { risk as defined by Ph+ve, MLL+, } \\
\text { and persistent (postconsolida- } \\
\text { tion) MRD+ve patients }\end{array}$ & $\begin{array}{l}\text { Multiple factors need to } \\
\text { be considered as shown } \\
\text { in Table } 3 .\end{array}$ \\
\hline Anthracyclines & $\begin{array}{l}\text { Tailored use } \\
\text { Less preferred due to } \\
\text { long-term risks }\end{array}$ & $\begin{array}{l}\text { Usually, a component of } \\
\text { therapy at standard } \\
\text { doses }\end{array}$ & $\begin{array}{l}\text { Usually omitted or lesser } \\
\text { number of doses in elderly ALL }\end{array}$ & - \\
\hline $\begin{array}{l}\text { Cranial radiation } \\
\text { prophylaxis }\end{array}$ & $\begin{array}{l}\text { Omitted in most mod- } \\
\text { ern protocols }\end{array}$ & Usual component & $\begin{array}{l}\text { Dose of } 12 \text { Gy for prophylaxis } \\
\text { and } 18 \text { Gy for CNS+ disease }\end{array}$ & $\begin{array}{l}\text { Concerns about long- } \\
\text { term cognitive and en- } \\
\text { docrine effects in chil- } \\
\text { dren. Fewer concerns in } \\
\text { adults }\end{array}$ \\
\hline
\end{tabular}

Abbreviations: ALL, acute lymphoblastic leukemia; AlloSCT, allogeneic stem cell transplantation; CNS, central nervous system; MRD, minimal residual disease; Peg, pegylated; Ph+ve, Philadelphia chromosome-positive; pre-B All, precursor B-cell; T-ALL, T-cell ALL.MLL, mixed lineage leukemia; BFM, Berlin-Frankfur-Munster;

70\%. ${ }^{36}$ Indian studies have shown 5-year EFS and OS of $50 \pm$ 7.4 and $61 \pm 7.6 \%$ for pediatric T-ALL treated on MCP-841 protocol and 5-year EFS of $38 \pm 6.2 \%$ for adult T-ALL treated with modified GMALL protocol. ${ }^{25,37}$ At our center, we use BFM-95 for adult T-ALL up to 50 years of age and a modified GMALL for older/or, less-fit patients.

\section{Case-2 Continued}

After completing BFM-95 induction IA, the bone marrow was in morphological $\mathrm{CR}$, but MRD by flow cytometry was positive $(0.24 \%)$. He received three courses of the high-risk regimen of BFM-95. Subsequently, his marrow became MRDnegative and he is currenlty on maintenance.

\section{Role of Minimal Residual Disease Assessment in Acute Lymphoblastic Leukemia}

A tailored approach based on the MRD status must be considered in all patients currently treated for ALL. ${ }^{38}$ The best technique (multi-parameter flow cytometry vs. PCRbased assessment) and time point (end of induction vs. end of consolidation), for assessment of MRD is still 
Table 2 Selected studies of adult ALL from India

\begin{tabular}{|c|c|c|c|c|c|c|c|c|}
\hline Type & Ph type & Center & City & $n$ & $\begin{array}{l}\text { Median age in } \\
\text { years(range) }\end{array}$ & Treatment & EFS\% (y) & OS\% \\
\hline \multirow{5}{*}{$\begin{array}{l}\text { Ph-negative } \\
\text { ALL }\end{array}$} & 1997-2003 & PGIMER $^{25}$ & Chandigarh & 118 & $>12$ & Modified BFM & $29(3)$ & NR \\
\hline & 1995-2009 & $\mathrm{CMC}^{79}$ & Vellore & 113 & $15-60$ & Modified GMALL ${ }^{\text {a }}$ & $51(5)$ & $51(5)$ \\
\hline & $2000-2013$ & $\mathrm{Cl}(14)$ & Chennai & 232 & $21(18-30)$ & BFM and GMALL & $36(5)$ & $39(5)$ \\
\hline & $2012-2018$ & $\mathrm{HCC}^{80}$ & Multiple & 572 & $21(15-29)$ & Multiple ${ }^{b}$ & $56(2)$ & $73(2)$ \\
\hline & $2013-2016$ & $\mathrm{TMH}^{81}$ & Mumbai & 349 & $15-25$ & BFM & $59(3)$ & $61(3)$ \\
\hline \multirow{3}{*}{$\begin{array}{l}\text { PH-positive } \\
\text { ALL }\end{array}$} & $2011-2016$ & $\mathrm{RGCl}^{82}$ & New Delhi & 63 & $35(14-76)$ & COG/UKALL & $31(4)$ & $46(4)$ \\
\hline & $2009-2012$ & $\mathrm{TMH}^{83}$ & Mumbai & 65 & $28(15-53)$ & MCP/BFM/other ${ }^{\mathrm{e}}$ & $30(2)$ & $29(2)$ \\
\hline & $2012-2017$ & $\mathrm{HCC}^{80}$ & Multiple & 158 & $21(15-29)$ & Multiple $^{\mathrm{b}, \mathrm{d}}$ & $47(2)$ & $67(2)$ \\
\hline
\end{tabular}

Abbreviations: ALL, acute lymphoblastic leukemia; BFM, Berlin-Frankfur-Munster; CI (WIA), cancer institute (WIA), Adyar; CMC, Christian Medical College; COG, Children's Oncology Group; EFS, event-free survival; GMALL, German multicenter study group for adult ALL; HCC, Hematology Cancer Consortium; MCP, Multicenter protocol-841; OS, overall survival; Ph+ve, Philadelphia chromosome-positive; PGIMER, Post Graduate Institute of Medical Education \& Research; RGCI, Rajiv Gandhi Cancer Institute, Dwarka; TMH, Tata Memorial Hospital; UKALL, United Kingdom Multicenter ALL protocol.

${ }^{\mathrm{a} O}$ Only T-cell ALL were analyzed in this study.

bediatric (87\%), adult (13\%); BFM (74\%), COG (8.5\%), MCP-841 (3.7\%), GMALL (10.4\%), hyper-CVAD (2.3\%), and others (1\%).

Imatinib till 2021, then dasatinib; alloSCT in 16 patients; and EFS was superior with alloSCT (36 vs. 27\%).

dimatinib, 83\% and dasatinib, $17 \%$.

unresolved. ${ }^{39,40}$ T-ALL patients take longer to clear MRD than B-ALL, and MRD may be assessed 2-3 months postinduction. At our center, we assess MRD postinduction and if positive, we move to the high-risk (HR 1,2,3) arm of the same protocol. MRD-ve patients continue with standard-dose consolidation therapy. Patients who become MRD-ve after further chemotherapy are considered for allogeneic stem cell transplantation (alloSCT) in CR1. Patients with persistent MRD post consolidation do poorly even with additional chemotherapy or an alloSCT (10-20\% long term survival). The decision-making in these patients has to be individualized - Table $\mathbf{3}$ and the overall approach presented in -Fig. 1).

\section{AlloSCT in CR1 in adult Acute Lymphoblastic Leukemia} Though alloSCT reduces relapses (by $10-15 \%$ ), the benefit has to be weighed against the risk of non-relapse mortality (NRM) and other long-term problems. The MRC UKALL12/ ECOG 2993 trial was the largest ("genetic randomization") trial comparing conventional therapy (adult-type ALL protocol) with allogenic transplant in CR1. Patients with matched donors received CR1 alloSCT while those without donors continued chemotherapy. Though alloSCT reduced relapses, this benefit was negated by increased NRM, especially in those older than 45 years. ${ }^{41}$ Thus, the decision to allotransplant must consider the disease risk (baseline, and MRD), patient's fitness (age, comorbidities, performance status), type of protocol being used (pediatricinspired vs. adult), donor-type for the procedure (matched vs. haploidentical vs. cord blood),experience of the center, and also the possibility of later access to novel therapies (chimeric antigen receptor $\mathrm{T}$ cells, blinatumomab, inotuzumab, etc.) - Table 3). ${ }^{42}$
Among these, MRD-positivity is the most critical disease factor determining the decision of alloSCT in CR1 in adults with ALL. For patients treated with intense chemotherapy protocols and achieve MRD-ve status, the use of alloSCT in CR1 may not be required despite the presence of other highrisk factors. ${ }^{43}$

When the decision has been made to proceed with an alloSCT, conditioning using myeloablative regimens using total body irradiation (TBI) are preferred in patients with ALL. ${ }^{44,45}$ At our center, for Ph-ve ALL, we reserve alloSCT in CR1 (myeloablative conditioning with fludarabine-busulfan) for young ( $<50$ years) and fit patients with one or more conventional high-risk features (high-risk cytogenetics, early thymic precursor [ETP] ALL) only when a matched sibling donor is available. In the absence of a matched sibling donor, these patients are usually treated in the high-risk arm of the BFM-95 protocol. However, if they have persistent MRD after consolidation therapy, the long-term chance of survival is $12 \%{ }^{46}$ In these patients, we offer alloSCT in CR1. Decisions on haploidentical transplants in these patients are taken after very detailed discussions.

\section{Treatment of Early Thymic Precursor Acute Lymphoblastic Leukemia}

The ETP ALL accounts for 15 to $35 \%$ of T-ALL and is characterized by a unique immunophenotype (cCD3 ${ }^{+}, \mathrm{sCD}^{-}, \mathrm{CD} 1 \mathrm{a}-$, $\mathrm{CD}^{+}, \mathrm{CD}^{+}, \mathrm{CD} 8-, \mathrm{CD} 5 \mathrm{dim}$, and positivity for stem cell and myeloid markers, including HLA-DR, CD13, CD33, CD34, or CD117). ${ }^{47,48}$ Outcomes are inferior (lower remission rates post-induction and higher MRD positivity), but may be improved by contemporary response-adapted treatment regimens (alloSCT in CR1 reserved for persistent MRD 
Table 3 How we choose a patient for CR1 alloSCT in adult ALL

\begin{tabular}{|c|c|c|c|}
\hline Factor & $\begin{array}{l}\text { Strongly consider } \\
\text { alloSCT in } C R 1^{\text {a }} \text { (Green) }\end{array}$ & $\begin{array}{l}\text { Discuss the option of } \\
\text { alloSCT in CR1 } 1^{\mathrm{b}} \text { (Yellow) }\end{array}$ & $\begin{array}{l}\text { AlloSCT in CR1 not } \\
\text { to be considered (Red) }\end{array}$ \\
\hline Baseline risk factors & $\begin{array}{l}\text { Ph+ve disease } \\
\text { MLL rearrangements } \\
\text { Complex karyotype }\end{array}$ & $\begin{array}{l}\text { ETP ALL } \\
\text { MPAL }\end{array}$ & No baseline risk factors \\
\hline MRD status & Positive postconsolidation & $\begin{array}{l}\text { Positive postinduction } \\
\text { but negative } \\
\text { postconsolidation }\end{array}$ & MRD negative \\
\hline Age group (y) & $<40-45$ & $45-60$ & $>60-65$ \\
\hline Donor & Fully matched sibling or MUD & Haploidentical donors & No donor available \\
\hline Center TRM with alloSCT & $5-10 \%$ & $10-20 \%$ & $>20 \%$ \\
\hline Patient factors & $\begin{array}{l}\text { - Committed patient and family } \\
\text { - Finances available } \\
\text { - Able to stay in local place } \\
\text { for 6-12 months }\end{array}$ & $\begin{array}{l}\text { Any one of these factors } \\
\text { missing }\end{array}$ & All these factors are missing \\
\hline
\end{tabular}

Abbreviations: AlloSCT, allogeneic stem cell transplantation; ALL, acute lymphoblastic leukemia; ETP, early thymic precursor; MPAL, mixed phenotypic acute leukemia; MRD, minimal residual disease; MUD: matched unrelated donor; MLL, mixed lineage leukemia; TRM, treatment-related mortality.

Note: In the "red" group, we usually do not offer alloSCT in CR1.

an the "green" group, we offer allotransplant in first complete remission (CR1) and strongly encourage patients to consider this option, especially when all factors are favorable.

bIn the "yellow" group, when any of the factors are not favorable, we have detailed discussions with the patient and family about the pros and cons and make an informed decision.

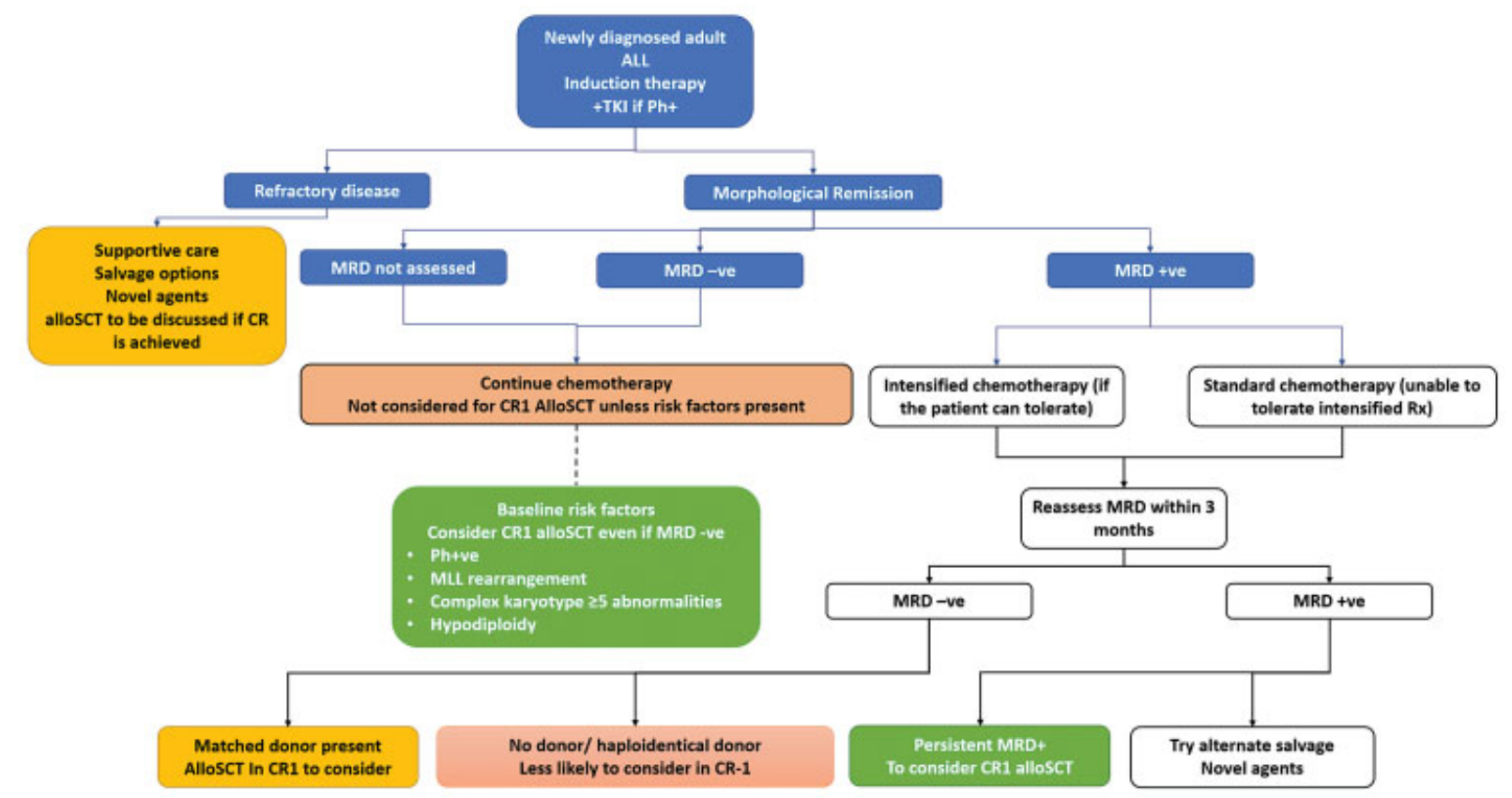

Fig. 1 Approach to adult acute lymphoblastic leukemia (ALL). Decision-making process for adult ALL in India. The green boxes represent strong indications for allogeneic stem cell transplantation (alloSCT) in first complete remission (CR1), where it would be offered to all those with a sibling donor. The yellow boxes represent situations where there is benefit from alloSCT in terms of reduction of relapses. However, the procedural risk may be high (e.g., only a haploidentical donor is available or when the patient is older or has multiple comorbidities). In these situations, the decision must be individualized after clear discussions with the patient and family. Decision-making must consider the center's experience in alternative-donor transplants. The blue box represents persistent MRD; these patients are at high risk of relapse. Their outcomes are poor with continued chemotherapy, but data also suggests that patients who are MRD+ve at the time of transplant have worse outcomes than those who undergo transplants with MRD-ve marrow. Hence, these situations also require detailed discussions. The red boxes are situations where alloSCT in CR1 is not considered (no donor, MRD-ve, and no high-risk features). MRD, minimal residual disease; Ph+ve, Philadelphia chromosome-positive;TKI, tyrosine kinase inhibitor. MLL, mixed lineage leukemia; 
positivity). ${ }^{35,49}$ The use of L-asparaginase may be important; hence "pediatric" type protocols may be preferred for ETP ALL over protocols such as hyper-CVAD. ${ }^{50}$ At this point, there is limited published data on ETP ALL from India. We currently treat adult ETP ALL with BFM-95 protocol on and reserve alloSCT for persistent MRD post consolidation.

\section{Case 3: Elderly Patient with Acute Lymphoblastic Leukemia}

A 73-year-old retired school teacher had been feeling unwell for 2 months. He had been diagnosed with anemia, and had received two packed red blood cells. A repeat blood count showed hemoglobin: $65 \times 10^{9} / \mathrm{L}(6.5 \mathrm{~g} / \mathrm{dL}), \mathrm{WBC}$ count: $2.3 \times 10^{9} / \mathrm{L}\left(2,300 / \mathrm{mm}^{3}\right)$, and platelet count: $45 \times$ $10^{9} / \mathrm{L}\left(45,000 / \mathrm{mm}^{3}\right)$. Bone marrow was replaced with lymphoblasts (CD19+, CD20+, CD3-ve, and pre-B ALL). BCR-ABL was negative. He had well-controlled hypertension, poorly controlled blood glucose, and took cardiac medications after bypass surgery for triple-vessel coronary artery disease 3 years ago. On examination, he was cheerful, accepting of his diagnosis, and had a performance status of 1 . Treatment options and outcomes were discussed in detail with the patient and the family.

Treatment of Elderly Acute Lymphoblastic Leukemia: Curative or Palliative Intent?

Outcomes of ALL patients over the age of 60 years is poor with conventional chemotherapy. The SEER database showed a 3year survival of $24 \%$ in 60 to 64 -year-old patients. The SEER database showed a 3-year survival of $24 \%$ in $60-64$-year-old patients, which dropped to $12 \%$ at $70-74$ years and $8 \%$ in those between $75-79$ years of age. ${ }^{5}$ The patient and family need to understand these bleak outcomes. CR after induction is achieved in less than half the patients, and a quarter may suffer early mortality. ${ }^{51}$ Though small studies have shown improvement in outcomes with more "intensive" regimens, ${ }^{52}$ these have not been consistently replicated.

We have a detailed discussion with older patients about the reality of the situation. The patient presented here had evident comorbidities which would limit delivery of intense chemotherapies. However, the family was insistent on trying whatever would be possible.

\section{Case-3 Continued}

The family wanted to consider some form of "curative" therapy despite understanding the risks. He started modified GMALL induction (steroids, $3 \times$ weekly doses of vincristine and one dose of daunorubicin). He had multiple complications (hyperglycemia, vincristine-induced ileus, and gram-negative sepsis), and required intensive care. Blood counts improved by week 5, and marrow on D35 was in remission. MRD assessment was not performed. The general condition had worsened considerably by this time, and the patient was deemed unfit for further intensive chemotherapy. He started an oral "maintenance" treatment with daily 6-mercaptopurine and weekly methotrexate.
Unfortunately. the disease relapsed after 5 months. The patient opted for home-based supportive care without further anticancer therapy.

The outcomes of relapsed ALL is dismal even with allogeneic transplantation. Some improvement in survival may be achieved with the newer agents like inotuzumab and blinatumomab. However, considering the costs involved in sourcing these newer agents, salvage therapies are not usually practical in these patients.

\section{Improving Outcomes in Elderly Acute Lymphoblastic Leukemia with Targeted Treatments: The Future Looks Bright}

The current approaches with conventional therapies are unlikely to make a huge difference in the outcomes of elderly ALL. Newer strategies with a combination of targeted agents and less-intense chemotherapy has shown benefit. Rituximab with GMALL protocol produced a modest 5 -year OS of $23 \%$ in patients with ALL > 55 years of age. ${ }^{53}$ Recent studies have shown improved outcomes in elderly ALL ( short-term survival $>50 \%$ ) with the use of inotuzumab and blinatumomab. ${ }^{54,55}$ Ironically, the outcomes of $\mathrm{Ph}+\mathrm{ve}$ ALL in the elderly may have improved due to the use of TKIs. Low-intensity chemotherapy with dasatinib produced a 5year OS of $36 \%$ in a European study where the median age was 69 years. ${ }^{56}$

\section{Case 4: Adult with Philadelphia Chromosome-Positive Acute Lymphoblastic Leukemia}

A 43-year-old male presented with a 4-week history of fatigue and intermittent fever; hemoglobin: $77 \times 10^{9} / \mathrm{L}(7.7 \mathrm{~g} / \mathrm{dL})$, WBC: $85 \times 10^{9} / \mathrm{L}\left(85,000 / \mathrm{mm}^{3}\right)$, and platelets: $48 \times 10^{9} / \mathrm{L}(48,000 /$ $\mathrm{mm}^{3}$ ) with $88 \%$ blasts in peripheral smear. Bone marrow examination and flow cytometry confirmed the diagnosis of pre-B-ALL. Conventional karyotyping showed 46, XY with $t$ $(9 ; 22)$ and peripheral blood was positive for BCR-ABL p190 transcripts. He was started on BFM-95 induction with dasatinib added on day 6 after the BCR-ABL report was available.

Ph+ve ALL accounts for approximately 25 to $30 \%$ of adult ALL and up to $50 \%$ of cases in older adults and the elderly. ${ }^{57}$ The addition of TKIs to chemotherapy improves CR rates (90-100\%) and the survival (38-54\%) in adult Ph+ve ALL. ${ }^{58-62}$

\section{Philadelphia Chromosome-Positive Acute Lymphoblastic Leukemia which Tyrosine Kinase Inhibitors to Choose and How to Add the Tyrosine Kinase Inhibitors?}

Dasatinib versus imatinib: there is no trial directly comparing dasatinib and imatinib for adult Ph+ve ALL. Crosstrial comparisons suggest that both produce similar CR after induction (>95\%). However, dasatinib treated patients are more likely to achieve complete molecular responses at 3 months (complete molecular response at $65 \%$ with dasatinib vs. 30 to $45 \%$ with imatinib) and better central nervous system penetration. ${ }^{58,61,62}$ In children 
with Ph+ve ALL, EFS (71 vs. $49 \%$ ) and OS (88 vs. $69 \%$ ) were superior with dasatinib when compared to imatinib. ${ }^{63}$ Mutations may develop during TKI therapy and 75\% of those with dasatinib resistance harbor the T315I mutation. ${ }^{56}$ Ponatinib produces a high complete molecular remission rate (77\%) and survival (3-year DFS of $79 \%$ ) in newly diagnosed $\mathrm{Ph}+\mathrm{ALL}$, but is currently not marketed in India. ${ }^{64}$ There is only one study with nilotinib in $\mathrm{Ph}+\mathrm{ve}$ ALL, and it showed good activity. ${ }^{65}$ Based on these results, and the recent availability of generics, we prefer to use dasatinib (start at $100 \mathrm{mg}$ OD and increase to $140 \mathrm{mg}$ OD if tolerated)in Ph+ALL. We may start at a lower dasatinib dose $(70 \mathrm{mg})$ in patients with an active infection. TKIresistant mutations, including $\mathrm{T} 315 \mathrm{I}$ mutations, can occur during therapy and have been described even at baseline in Ph+ve ALL.56 We don't perform mutation studies at baseline in Ph+ALL and do this testing only if the patients develop resistance.

\section{Case-4 Continued}

During induction, the patient had grade- 4 neutropenia complicated by neutropenic sepsis and grade-2 mucositis which delayed the completion. Postinduction the bone marrow was in CR, and the patient was counseled for an alloSCT but there was no matched donor available. Post-first-phase consolidation, patient had a major molecular response (MMR). However, in the absence of a fully matched donor, he continued dasatinib with chemotherapy. Monitoring of his disease status is being done by quantitative BCR-ABL assessment by PCR once in 3 months.

\section{Philadelphia Chromosome-Positive Acute Lymphoblastic Leukemia: Intensity of Chemotherapy} Several studies from Europe (GIMEMA, EWALL, PETHEMA, and GRALL) have shown that less intensive chemotherapy (steroids \pm vincristine) combined with TKI (imatinib/dasatinib) results in high CR rates (95-100\%) and low induction mortality $(<3 \%)$ in $\mathrm{Ph}+\mathrm{ve}$ ALL. ${ }^{56,62,66-68}$ GRAAPH-2005 showed lesser mortality and comparable molecular responses with reduced intensity induction and imatinib (5-year os [48.3 vs. 43\%]). ${ }^{62}$ However, post-remission consolidation chemotherapy has to be continued, and allogeneic transplant must be considered in CR1, whenever feasible. We use reduced-intensity induction (steroid, vincristine, and dasatinib) in adult $\mathrm{Ph}+\mathrm{ve}$ ALL, followed by the continuation of conventional consolidation and maintenance chemotherapy (with TKI in all phases) for those not planned for CR1 alloSCT. Since the optimal duration of TKI is not known, we choose to give it for at least 5 years.

\section{What is the status of alloSCT in CR1 in Philadelphia Chromosome-Positive Acute Lymphoblastic Leukemia?}

Pediatric studies have reported equivalent outcomes with chemotherapy plus TKI or alloSCT, but for adults, alloSCT remains the standard. ${ }^{69,70}$ In the TKI era, an OS of 35 to $55 \%$ at 2 to 5 years has been achieved without alloSCT, but the OS increases to 60 to $70 \%$ when patients are allotransplanted in CR1. ${ }^{60,70}$ The best outcomes with alloSCT, are seen in a young fit patient with molecular remission following TKI-based induction and with a matched sibling donor or a fully matched unrelated donor. In older adults and in those with comorbidities, the risk of NRM negates the benefit of transplant. Even after alloSCT, continued TKI reduces relapses and must be started as soon as stable engraftment is achieved. ${ }^{71}$ Unresolved issues are: (1) Whether early CMR (at 3 months) can omit the alloSCT and do well with chemotherapy+TKI alone?,(2) whether the use of more potent third-generation TKI (ponatinib) will obviate the benefit of alloSCT?, and (3) can alloSCT overcome the negative prognostic impact of factors like highrisk genetics (IKZF2 mutations, T315I mutation, and CKND2A/2B deletions) and persistent MRD?

Our practice offers CR1 alloSCT for all young and fit adult patients with Ph+ve ALL who have matched sibling donors who have achieved at least a major molecular response with induction therapy. We continue TKI maintenance therapy posttransplant for at least 5 years.

\section{Case 5: Patient with Relapsed Acute Lymphoblastic Leukemia}

A 30-year-old male was diagnosed with pre-B ALL 4 years ago and was treated at another center with GMALL protocol. He had achieved complete response by day 30 and marrow and completed intensive chemotherapy and maintenance 6 months back. He had recently noted petechial spots and had pancytopenia due to relapsed B-ALL. He had come to us for further management.

\section{How to choose patients for salvage therapy in relapsed ALL?}

The outcomes of relapsed is poor, with long-term survival of 7\% reported from the large UKALL12/ ECOG 2993 study. ${ }^{72}$ However, among patients who were able to achieve CR2 with salvage, and allografted from an HLA-matched sibling, the outcome improved to approximately $23 \%$ in the same study. Other factors that determine better outcomes with salvage therapies are younger age and longer remission duration. Isolated nervous system or testicular relapses, or MRD-ve disease at the end of salvage chemotherapy will also predict better outcomes. ${ }^{73,74}$

At our center, considering that there is limited availability of stem-cell transplant facilities and a long waitlist, we offer salvage for select patients (long treatment-free interval, and ability undergo alloSCT). Since intensive chemotherapy alone without consolidation allogeneic transplant is unlikely to cure relapsed ALL, we offer only palliative therapy for patients who are not planned for allogeneic transplantation. An important factor enabling the decision-making is the achievement of an MRD-ve CR2 status after salvage chemotherapy. 


\section{Case-5 Continued}

We counseled the patient regarding treatment options. He achieved MRD-ve remission (CR2) after salvage with the FLAG (fludarabine, cytarabine, and granulocyte colony stimulating factor) regimen and received an allogenic transplant from his fully matched sibling. He is currently in remission 6 months post alloSCT.

\section{Optimum Salvage Regimens}

Randomized trials have not compared the salvage regimens used in relapsed ALL. Wide variations have been reported in the responses with these regimens which have been extensively reviewed elsewhere. ${ }^{75}$ About 40 to $50 \%$ of adults with relapsed ALL achieve CR2 after salvage. FLAG \pm idarubicin is a popular option, especially in patients who have had early relapses. It is reasonable to use regimens containing steroids and/or L-asparaginase with high dose cytarabine like the UKALL and BFM relapse protocols in patients with late relapse. Hyper-CVAD is another option that produces $>40 \%$ CR in relapsed ALL. ${ }^{76}$

Newer drugs have significantly improved $C R$ rates, MRD-ve rates, and survival in relapsed patients. Drugs like inotuzumab and blinatumomab have shown efficacy in large randomized trials and should be incorporated if a given patient can access these agents. ${ }^{54,77}$ Chimeric antigen receptor T cell therapy (CAR-T) is another radical strategy that has dramatically improved outcomes in relapsed ALL. ${ }^{78}$

\section{Key Take-Home Points}

- For a newly diagnosed fit, young adult ( $<50$ years), we prefer to use a "pediatric" regimen (-Fig. 1).

- MRD assessment must be done at the end of induction, and intensification of therapy, and allogenic transplant in CR1 must be considered for those who are MRD+ve $(>0.01 \%)$

- For Ph+ve ALL, induction therapy can consist of only vincristine, steroids, and TKI (dasatinib is preferred over imatinib). Consider alloSCT in CR1 whenever there is a fully matched donor available.

- Consider rituximab in CD20+ adult ALL.

- For the elderly ALL, outcomes are poor, and a clear discussion is essential before starting intensive chemotherapy regimens.

- Outcomes are poor in relapsed ALL and salvage therapy must be planned for selected patients when resources are limited. The following features predict better survival in relapsed disease: late relapse, good general condition, and achievement of MRD-ve status after salvage therapy. When these factors are not present, palliative treatment should be discussed

- Since optimum therapy of ALL requires very long-term commitment, appropriate strategies must be in place for social and psychological support to ensure adherence to treatment.

Funding

No external sources of funding
Conflicts of Interest

None of the authors have any relevant conflicts of interests to declare.

\section{References}

1 Pui C-H, Evans W EA 50-year journey to cure childhood acute lymphoblastic leukemia. Semin Hematol 2013;50(03):185-196

2 Schultz K R, Bowman W P, Aledo A, et al. Improved early event-free survival with imatinib in Philadelphia chromosome-positive acute lymphoblastic leukemia: a children's oncology group study. J Clin Oncol 2009;27(31):5175-5181

3 Lennmyr E, Karlsson K, Ahlberg L, et al. Swedish Adult Acute Lymphoblastic Leukaemia Group (SVALL). Survival in adult acute lymphoblastic leukaemia (ALL): A report from the Swedish ALL Registry. Eur J Haematol 2019;103(02):88-98

4 Stock W, Luger S M, Advani A S, et al. A pediatric regimen for older adolescents and young adults with acute lymphoblastic leukemia: results of CALGB 10403. Blood 2019;133(14):1548-1559

5 Geyer M B, Hsu M, Devlin S M, Tallman M S, Douer D, Park J HOverall survival among older US adults with ALL remains low despite modest improvement since 1980: SEER analysis. Blood 2017;129(13):1878-1881

6 DeAngelo D J, Jabbour E, Advani A. Recent advances in managing acute lymphoblastic leukemia. Am Soc Clin Oncol Educ Book 2020;40(40):330-342

7 Toft N, Birgens H, Abrahamsson J, et al. Results of NOPHO ALL2008 treatment for patients aged 1-45 years with acute lymphoblastic leukemia. Leukemia 2018;32(03):606-615

8 DeAngelo D J, Stevenson K E, Dahlberg S E, et al. Long-term outcome of a pediatric-inspired regimen used for adults aged $18-50$ years with newly diagnosed acute lymphoblastic leukemia. Leukemia 2015;29(03):526-534

9 Huguet F, Leguay T, Raffoux E, et al. Pediatric-inspired therapy in adults with Philadelphia chromosome-negative acute lymphoblastic leukemia: the GRAALL-2003 study. J Clin Oncol 2009;27 (06):911-918

10 Patel B, Kirkwood A A, Dey A, et al. Pegylated-asparaginase during induction therapy for adult acute lymphoblasticleukaemia: toxicity data from the UKALL14 trial. Leukemia 2017;31(01):58-64

11 Jain P, Korula A, Deshpande P, et al. Adult acute lymphoblastic leukemia: limitations of intensification of therapy in a developing country. J Glob Oncol 2018;4:1-12

12 Ganesan P, Sagar T G, Kannan K, et al. Acute lymphoblastic leukemia in young adults treated with intensive "pediatric" type protocol. Indian J Hematol Blood Transfus 2018;34(03): 422-429

13 United Nations, Department of Economic and Social Affairs. The World Population Prospects: 2015 Revision. Available at:https:// www.un.org/en/development/desa/publications/world-population-prospects-2015-revision.html\#: :text=The\%20current\% 20world\%20population\%20of,2015\%20Revision\%E2\%80\%9D\%2C\% 20launched\%20today. Accessed June 18, 2021

14 Ganesan P, Jain H, Bagal B, et al. Outcomes in adolescent and young adult (AYA) acute lymphoblastic leukemia (ALL): a report from the Indian acute leukemia research database (INwARD) of the hematology cancer consortium (HCC. Blood 2019;134(01): 1306

15 Philip C, George B, Ganapule A, et al. Acute myeloid leukaemia: challenges and real world data from India. Br J Haematol 2015;170 (01):110-117

16 Biswal S, Godnaik C. Incidence and management of infections in patients with acute leukemia following chemotherapy in general wards. Ecancermedicalscience 2013;7:310

17 Curran E, Stock W. How I treat acute lymphoblastic leukemia in older adolescents and young adults. Blood 2015;125(24): $3702-3710$ 
18 Rytting M E, Jabbour E J, O’Brien S M, Kantarjian H MAcute lymphoblastic leukemia in adolescents and young adults. Cancer 2017;123(13):2398-2403

19 Boissel N, Baruchel A. Acute lymphoblastic leukemia in adolescent and young adults: treat as adults or as children ? Blood 2018;132 (04):351-361

20 Möricke A, Reiter A, Zimmermann M, et al. German-AustrianSwiss ALL-BFM Study Group. Risk-adjusted therapy of acute lymphoblastic leukemia can decrease treatment burden and improve survival: treatment results of 2169 unselected pediatric and adolescent patients enrolled in the trial ALL-BFM 95. Blood 2008;111(09):4477-4489

21 Muffly L, Alvarez E, Lichtensztajn D, Abrahão R, Gomez S L, Keegan T. Patterns of care and outcomes in adolescent and young adult acute lymphoblastic leukemia: a population-based study. Blood Adv 2018;02(08):895-903

22 Pui C H, Pei D, Sandlund J T, et al. Long-term results of St Jude Total Therapy Studies 11, 12, 13A, 13B, and 14 for childhood acute lymphoblastic leukemia. Leukemia 2010;24(02):371-382

23 Maury S, Chevret S, Thomas X, et al. Rituximab in B-lineage adult acute lymphoblastic leukemia. N Engl J Med 2016;375(11): 1044-1053

24 Bhatia S, Landier W, Shangguan M, et al. Nonadherence to oral mercaptopurine and risk of relapse in Hispanic and non-Hispanic white children with acute lymphoblastic leukemia: a report from the children's oncology group. J Clin Oncol 2012;30(17): 2094-2101

25 Malhotra P, Varma S, Varma N, et al. Outcome of adult acute lymphoblastic leukemia with BFM protocol in a resource-constrained setting. Leuk Lymphoma 2007;48(06):1173-1178

26 Jatia S, Prasad M, Paradkar A, et al. Holistic support coupled with prospective tracking reduces abandonment in childhood cancers: a report from India. Pediatr Blood Cancer 2019;66(06):e27716

27 Roy N Moulik, Kulkarni K P, Kumar A. Tracking children with acute lymphoblastic leukemia who abandoned therapy: experience, challenges, parental perspectives, and impact of treatment subsidies and intensified counseling. Pediatr Hematol Oncol 2016;33 (05):327-337

28 Alam A, Kumar A. Impact of financial support and focussed group counselling on treatment abandonment in children with acute lymphoblastic leukaemia. Experience over 22 years from North India. Psychooncology 2019;28(02):372-378

29 Dores G M, Devesa S S, Curtis R E, Linet M S, Morton L MAcute leukemia incidence and patient survival among children and adults in the United States, 2001-2007. Blood 2012;119(01): 34-43

30 Marks D I, Paietta E M, Moorman A V, et al. T-cell acute lymphoblastic leukemia in adults: clinical features, immunophenotype, cytogenetics, and outcome from the large randomized prospective trial (UKALL XII/ECOG 2993. Blood 2009;114 (25):5136-5145

31 Patrick K, Vora A. Update on biology and treatment of T-cell acute lymphoblastic leukaemia. Curr Opin Pediatr 2015;27(01):44-49

32 Patrick K, Wade R, Goulden N, et al. Improved outcome for children and young people with T-acute lymphoblastic leukaemia: results of the UKALL 2003 trial. Blood 2014;124(21):3702

33 Möricke A, Zimmermann M, Valsecchi M G, et al. Dexamethasone vs prednisone in induction treatment of pediatric ALL: results of the randomized trial AIEOP-BFM ALL 2000. Blood 2016;127(17): 2101-2112

34 Litzow M R, Ferrando A AHow I treat T-cell acute lymphoblastic leukemia in adults. Blood 2015;126(07):833-841

35 Hoelzer D, Thiel E, Arnold R, et al. Successful subtype oriented treatment strategies in adult T-ALL; results of 744 patients treated in three consecutive GMALL studies. Blood 2009;114:324

36 Raetz E A, Teachey D TT-cell acute lymphoblastic leukemia. Hematology (Am Soc Hematol Educ Program 2016;2016(01): 580-588
37 Arya L S, Padmanjali K S, Sazawal S, et al. Childhood T-lineage acute lymphoblastic leukemia: management and outcome at a tertiary care center in North India. Indian Pediatr 2011;48(10): 785-790

38 Della Starza I, Chiaretti S, De Propris M S, et al. Minimal residual disease in acute lymphoblastic leukemia: technical and clinical advances. Front Oncol 2019;09(726):726

39 Ribera J M, Oriol A, Morgades M, et al. Treatment of high-risk Philadelphia chromosome-negative acute lymphoblastic leukemia in adolescents and adults according to early cytologic response and minimal residual disease after consolidation assessed by flow cytometry: final results of the PETHEMA ALL-AR-03 trial. J Clin Oncol 2014;32(15):1595-1604

40 Dhédin N, Huynh A, Maury S, et al.GRAALL group. Role of allogeneic stem cell transplantation in adult patients with $\mathrm{Ph}$ negative acute lymphoblastic leukemia. Blood 2015;125(16): 2486-2496

41 Goldstone A H, Richards S M, Lazarus H M, et al. In adults with standard-risk acute lymphoblastic leukemia, the greatest benefit is achieved from a matched sibling allogeneic transplantation in first complete remission, and an autologous transplantation is less effective than conventional consolidation/maintenance chemotherapy in all patients: final results of the International ALL trial (MRC UKALL XII/ECOG E2993. Blood 2008;111(04): 1827-1833

42 El F akih R, Ahmed S, Alfraih F, Hanbali A. Hematopoietic cell transplantation for acute lymphoblastic leukemia in adult patients. Hematol Oncol Stem Cell Ther 2017;10(04):252-258

43 Giebel S, Marks D I, Boissel N, et al. Hematopoietic stem cell transplantation for adults with Philadelphia chromosome-negative acute lymphoblastic leukemia in first remission: a position statement of the European Working Group for Adult Acute Lymphoblastic Leukemia (EWALL) and the Acute Leukemia Working Party of the European Society for Blood and Marrow Transplantation (EBMT. Bone Marrow Transplant 2019;54(06): 798-809

44 Abdelaty M M, Gawaly A, Fathy G M, Kabbash I, Taha A. Irradiation free conditioning regimen is associated with high relapse rate in Egyptian patients with acute lymphoblastic leukemia following allogeneic hematopoietic stem cell transplantation. J Egypt Natl Canc Inst 2020;32(01):28

45 Park H, Byun J M, Koh Y, et al. Comparison of different conditioning regimens in allogeneic hematopoietic stem-cell transplantation shows superiority of total body irradiation-based regimen for younger patients with acute leukemia: a nationwide study. Clin Lymphoma Myeloma Leuk 2019;19(11):e605-e615

46 Gökbuget N, Kneba M, Raff T, et al.German Multicenter Study Group for Adult Acute Lymphoblastic Leukemia. Adult patients with acute lymphoblastic leukemia and molecular failure display a poor prognosis and are candidates for stem cell transplantation and targeted therapies. Blood 2012;120(09): 1868-1876

47 Jain N, Lamb A V, O’Brien S, et al. Early T-cell precursor acute lymphoblastic leukemia/lymphoma (ETP-ALL/LBL) in adolescents and adults: a high-risk subtype. Blood 2016;127(15):1863-1869

48 Haydu J E, Ferrando A AEarly T-cell precursor acute lymphoblastic leukaemia. Curr Opin Hematol 2013;20(04):369-373

49 Wood B L, Winter S S, Dunsmore K P, et al. T-lymphoblastic leukemia (T-ALL) shows excellent outcome, lack of significance of the early thymic precursor (ETP) immunophenotype, and validation of the prognostic value of end-induction minimal residual disease (MRD) in Children's Oncology Group (COG) study AALL0434. Blood 2014;124(21):1

50 Shah B D, Borate U, Kota V K, et al. Multi-institution review of adult early T-cell precursor acute lymphoblastic leukemia/lymphoma (ETP-ALL. Blood 2015;126(23):3715

51 Gökbuget N. How I treat older patients with ALL. Blood 2013;122 (08):1366-1375 
52 Ribera J M, García O, Gil C, et al.PETHEMA Group. Comparison of intensive, pediatric-inspired therapy with non-intensive therapy in older adults aged 55-65 years with Philadelphia chromosomenegative acute lymphoblastic leukemia. Leuk Res 2018;68:79-84

53 Goekbuget N, Beck J, Brueggemann M, et al. Moderate intensive chemotherapy including CNS-prophylaxis with liposomal cytarabine is feasible and effective in older patients with Ph-negative acute lymphoblastic leukemia (ALL): results of a prospective trial from the German multicenter study group for adult ALL (GMALL. Blood 2012;120(21):1493

54 Kantarjian H, Ravandi F, Short N J, et al. Inotuzumab ozogamicin in combination with low-intensity chemotherapy for older patients with Philadelphia chromosome-negative acute lymphoblastic leukaemia: a single-arm, phase 2 study. Lancet Oncol 2018;19 (02):240-248

55 Advani A S, Moseley A, O'Dwyer K M, et al. Results of SWOG 1318: a phase 2 trial of blinatumomab followed by pomp (prednisone, vincristine, methotrexate, 6-mercaptopurine) maintenance in elderly patients with newly diagnosed Philadelphia chromosome negative B-cell acute lymphoblastic leukemia. Blood 2018;132 (01):33

56 Rousselot P, Coudé M M, Gokbuget N, et al. European Working Group on Adult ALL (EWALL) group. Dasatinib and low-intensity chemotherapy in elderly patients with Philadelphia chromosome-positive ALL. Blood 2016;128(06):774-782

57 Secker-Walker L M, Craig J M, Hawkins J M, Hoffbrand A VPhiladelphia positive acute lymphoblastic leukemia in adults: age distribution, BCR breakpoint and prognostic significance. Leukemia 1991;5(03):196-199

58 Daver N, Thomas D, Ravandi F, et al. Final report of a phase II study of imatinib mesylate with hyper-CVAD for the front-line treatment of adult patients with Philadelphia chromosome-positive acute lymphoblastic leukemia. Haematologica 2015;100(05): 653-661

59 Lim S N, Joo Y D, Lee K H, et al. Long-term follow-up of imatinib plus combination chemotherapy in patients with newly diagnosed Philadelphia chromosome-positive acute lymphoblastic leukemia. Am J Hematol 2015;90(11):1013-1020

60 Bassan R, Rossi G, Pogliani E M, et al. Chemotherapy-phased imatinib pulses improve long-term outcome of adult patients with Philadelphia chromosome-positive acute lymphoblastic leukemia: Northern Italy leukemia group protocol 09/00. J Clin Oncol 2010;28(22):3644-3652

61 Ravandi F, O'Brien S M, Cortes J E, et al. Long-term follow-up of a phase 2 study of chemotherapy plus dasatinib for the initial treatment of patients with Philadelphia chromosome-positive acute lymphoblastic leukemia. Cancer 2015;121(23):4158-4164

62 Chalandon Y, Thomas X, Hayette S, et al.Group for Research on Adult Acute Lymphoblastic Leukemia (GRAALL). Randomized study of reduced-intensity chemotherapy combined with imatinib in adults with Ph-positive acute lymphoblastic leukemia. Blood 2015;125(24):3711-3719

63 Shen S, Chen X, Cai J, et al. Effect of dasatinib vs imatinib in the treatment of pediatric Philadelphia chromosome-positive acute lymphoblastic leukemia: a randomized clinical trial. JAMA Oncol 2020;6(03):358-366

64 Jabbour E, Kantarjian H, Ravandi F, et al. Combination of hyperCVAD with ponatinib as first-line therapy for patients with Philadelphia chromosome-positive acute lymphoblastic leukaemia: a single-centre, phase 2 study. Lancet Oncol 2015;16(15): 1547-1555

65 Kim D Y, Joo Y D, Lim S N, et al.Adult Acute Lymphoblastic Leukemia Working Party of the Korean Society of Hematology. Nilotinib combined with multiagent chemotherapy for newly diagnosed Philadelphia-positive acute lymphoblastic leukemia. Blood 2015;126(06):746-756

66 Ribera J M, García O, Montesinos P, et al. Treatment of young patients with Philadelphia chromosome-positive acute lympho- blastic leukaemia using increased dose of imatinib and deintensified chemotherapy before allogeneic stem cell transplantation. Br J Haematol 2012;159(01):78-81

67 Vignetti M, Fazi P, Cimino G, et al. Imatinib plus steroids induces complete remissions and prolonged survival in elderly Philadelphia chromosome-positive patients with acute lymphoblastic leukemia without additional chemotherapy: results of the Gruppo Italiano Malattie Ematologiche dell'Adulto (GIMEMA) LAL0201-B protocol. Blood 2007;109(09):3676-3678

68 Rea D, Legros L, Raffoux E, et al.Intergroupe Français des Leucémies Myéloïdes Chronique; Group for Research in Adult Acute Lymphoblastic Leukemia. High-dose imatinib mesylate combined with vincristine and dexamethasone (DIV regimen) as induction therapy in patients with resistant Philadelphiapositive acute lymphoblastic leukemia and lymphoid blast crisis of chronic myeloid leukemia. Leukemia 2006;20(03): 400-403

69 Schultz K R, Carroll A, Heerema N A, et al.Children's Oncology Group. Long-term follow-up of imatinib in pediatric Philadelphia chromosome-positive acute lymphoblastic leukemia: children's oncology group study AALL0031. Leukemia 2014;28(07): 1467-1471

70 Fielding A K, Rowe J M, Buck G, et al. UKALLXII/ECOG2993: addition of imatinib to a standard treatment regimen enhances long-term outcomes in Philadelphia positive acute lymphoblastic leukemia. Blood 2014;123(06):843-850

71 Giebel S, Czyz A, Ottmann O, et al. Use of tyrosine kinase inhibitors to prevent relapse after allogeneic hematopoietic stem cell transplantation for patients with Philadelphia chromosome-positive acute lymphoblastic leukemia: a position statement of the Acute Leukemia Working Party of the European Society for Blood and Marrow Transplantation. Cancer 2016;122 (19):2941-2951

72 Fielding A K, Richards S M, Chopra R, et al.Medical Research Council of the United Kingdom Adult ALL Working Party Eastern Cooperative Oncology Group. Outcome of 609 adults after relapse of acute lymphoblastic leukemia (ALL); an MRC UKALL12/ECOG 2993 study. Blood 2007;109(03):944-950

73 Locatelli F, Schrappe M, Bernardo M E, Rutella S. How I treat relapsed childhood acute lymphoblastic leukemia. Blood 2012; 120(14):2807-2816

74 Gökbuget N, Stanze D, Beck J, et al.German Multicenter Study Group for Adult Acute Lymphoblastic Leukemia. Outcome of relapsed adult lymphoblastic leukemia depends on response to salvage chemotherapy, prognostic factors, and performance of stem cell transplantation. Blood 2012;120(10):2032-2041

75 Frey N V, Luger S MHow I treat adults with relapsed or refractory Philadelphia chromosome-negative acute lymphoblastic leukemia. Blood 2015;126(05):589-596

76 Faderl S, Thomas D A, O'Brien S, et al. Augmented hyper-CVAD based on dose-intensified vincristine, dexamethasone, and asparaginase in adult acute lymphoblastic leukemia salvage therapy. Clin Lymphoma Myeloma Leuk 2011;11(01):54-59

77 Kantarjian H, Stein A, Gökbuget N, et al. Blinatumomab versus chemotherapy for advanced acute lymphoblastic leukemia. N Engl J Med 2017;376(09):836-847

78 Park J H, Rivière I, Gonen M, et al. Long-term follow-up of CD19 CAR therapy in acute lymphoblastic leukemia. N Engl J Med 2018; 378(05):449-459

79 Abraham A, George B, Ahmed R, et al. Outcome of treatment with a low cost protocol in adults with $\mathrm{T}$ cell acute lymphoblastic leukemia in a tertiary care center in India. Leuk Lymphoma 2014; 55(04):947-949

80 Ganesan P, Jain H, Bagal B, et al. Outcomes in adolescent and young adult acute lymphoblastic leukaemia: a report from the Indian Acute Leukaemia Research Database (INwARD) of the Hematology Cancer Consortium (HCC. Br J Haematol 2021;193 (01):e1-e4 
594 Management of Adult Acute Lymphoblastic Leukemia Ganesan, Kayal

81 Rajendra A, Jain H, Bonda V NA, et al. Outcomes and prognostic factors in adolescents and young adults with ALL treated with a modified BFM-90 protocol. Blood Adv 2021;5(05):1178-1193

82 Agrawal N, Verma P, Yadav N, et al. Outcome of Philadelphia positive acute lymphoblastic leukemia with or without allogeneic stem cell transplantation in a retrospective study. Indian J Hematol Blood Transfus 2019;35(02):240-247

83 Dangi U, Senagar M, Menon H. Treatment outcomes in Ph+ALL-a single center experience. Indian J Hematol Blood Transfus 2013; 29(04):274-400 